\title{
Driving Forces in Carbon Dioxide Emissions of the Hungarian Transport Sector
}

\author{
Olivér Hortay ${ }^{1,2^{\star}}$, Tamás Pálvölgyi \\ 1 Department of Environmental Economics, Faculty of Economic and Social Sciences, Budapest University of Technology and \\ Economics, H-1117 Budapest, Magyar tudósok körútja 2., Hungary \\ 2 Századvég Economic Research Institute, H-1037 Budapest, Hidegkuti Nándor u. 8-10., Hungary \\ * Corresponding author, e-mail: hortay@eik.bme.hu
}

Received: 27 February 2020, Accepted: 28 February 2020, Published online: 14 September 2021

\begin{abstract}
This article examines the evolution of the long-lasting trends and factors affecting the transport sector, which is responsible for a significant part of Hungarian carbon dioxide emissions. Empirical evidence suggests that the primary driving forces behind emissions from cars are stock development and carbon intensity. In freight transport, the primary driver of decarbonization is the rate of rail freight in total freights. By 2030, motorization and the size of cars will probably increase, so no significant emission reductions are expected in this area. In contrast, the increasing proportion of rail traffic can be a substantial decarbonization reserve. By 2030 , carbon dioxide emissions from passenger cars could increase by 1.5 million tonnes and from freight transport could decrease by 1 million tonnes, which would mean a further increase in the sector's aggregate pollution.
\end{abstract}

\section{Keywords}

carbon dioxide emission, decarbonization, transportation, Hungary

\section{Introduction}

In 2015, a significant number of countries around the world declared in the Paris Agreement that they would step up their efforts to reduce greenhouse gas (GHG) emissions in the future, thereby mitigating climate change caused by humanity (UNFCCC, 2015). Although the transition to a low-carbon economy is expected to affect all sectors, the measures will result in a deep transformation of high-emission activities. In 2014, three significant areas, energy $(49.04 \%)$, transport $(20.45 \%)$ and industrial production (19.96\%), were responsible for most of the global carbon emissions (Ritchie and Roser, 2020), so decarbonization of the transport sector is an inevitable task in mitigating climate change.

The share of transport emissions in the European Union is above the global average: in $201823.2 \%$ of the total GHG and $27.3 \%$ of the total carbon dioxide emissions was related to the transport of persons or goods (Eurostat, 2020)' ${ }^{1}$. Due to the high proportion, the transport policy, which is currently being identified by the White Paper, is appearing

1 Although the Eurostat database treats household and non-residential transport demand separately, these shares refer to the sum of the two. in the EU's climate policy (European Commission, 2011). One of the main goals of the strategy is to reduce the sector's current $\mathrm{CO}_{2}$ emissions by 60 per cent by 2050 . Although the share of transport emissions in Hungary are slightly below the EU average, ambitious targets will also pose significant challenges.

In Hungary, the most important policy measure for decarbonization of transport is the promotion of electrification. Accordingly, Ányos Jedlik's Plan 2.0, adopted by the government in 2019, aims to create the conditions necessary for the rapid expansion of electromobility, such as improving the charging infrastructure or providing incentives for fleet replacement (Ministry for Innovation and Technology, 2019) $)^{2}$. As the electrification of transport presents significant challenges and opportunities for the entire electricity grid, these are highlighted in the government's newly adopted National Energy Strategy (Ministry for Innovation and Technology, 2020a) and National Energy and Climate Plan (Ministry for Innovation and

2 The strategy aims to realize 450,000 electric vehicles and 45,000 electric chargers by 2030 . 
Technology, 2020b). While electrification is a promising solution, its potential for use in freight transport is limited. While electrification is a promising solution, the modal split of freight transport is expected to be required to achieve ambitious mitigation goals.

The aim of this article is to assess long term tendencies in $\mathrm{CO}_{2}$ emissions from the Hungarian transport sector and identify transport-related socio-economic drivers. A brief overview of the literature on policy interventions and the characteristics of the Hungarian transport sector is presented. Decomposition of $\mathrm{CO}_{2}$ emission of the sector and its main drivers are also assessed. Finally, the article summarizes the conclusions and the policy implications.

\section{Literature review}

In the last decades, several European studies predicted a significant reduction in carbon dioxide emissions from the transport sector. Because of expected technological developments, forecasts estimated a substantial improvement in energy intensity (for example, Kousoulidou et al., 2008), which outweighed the impact of increasing demand. Alongside new technologies, early literature attributes positive effects to biofuels, which can further reduce greenhouse gas emissions (Pasaoglu et al., 2012).

However, for the time being, new technologies, biofuels and policy interventions in the transport sectors of many countries have not fulfilled their expectations. Researchers have previously identified frictions in all three areas that could harm decarbonization. Abrell (2010) compares the types of state intervention and considers that, due to the many market distorting effects on the sector, new measures are no longer increasing the welfare. Koponen et al. (2013) find that greenhouse gas emissions across the entire value chain of biofuels are complicated to estimate, which represents a significant barrier to technology judgment and ideal regulation. According to Casals et al. (2016), while electromobility has a positive effect on airborne dust emissions, it will not have a decarbonization effect without modifying the European energy mix.

Andreoni and Galmarini (2012) used the decomposition procedure to examine the factors responsible for $\mathrm{CO}_{2}$ emissions in the European transport sector. According to the results, besides energy intensity, the two most important drivers are economic growth and the sub-sectoral structure and modal split in the transport sector. In general, increasing the share of rail transport can reduce the carbon footprint of the sector. In other words, if the decline in energy intensity does not offset the additional needs resulting from economic growth, freight should be directed to the railways. Also, the carbon intensity of rail transport is lower regardless of the fuel used to drive the locomotive (Kim and Wee, 2009).

For the transport sector, Hungary faces similar challenges as other member states of the European Union. In many ways, the years following the change of regime were a crucial period for the industry. Hook (1999) provides a detailed overview of the period from an economic, development policy, social and environmental perspective. The carbon dioxide emissions of the Hungarian transport sector, its effects on climate change and possible solutions are presented by Tánczos and Török (2008). Similarly to the findings of the international literature, increasing the proportion of railway traffic in Hungary has a significant decarbonization potential, but this requires a low-carbon energy mix (Török, 2014). In addition to differentiating the structure of transport, other aspects are worth considering. Buzási and Csete (2015) point out that due to the unique characteristics of Hungarian cities, they require different climate change interventions in the transport sector, both in terms of mitigation and adaptation. Green solutions are also becoming more and more critical in the corporate supply chain, and corporate transport is also expected to put increasing pressure on policymakers (Vörösmarty and Dobos, 2019).

\section{Evaluation}

Nowadays, carbon dioxide emissions from the transport sector account for $23.3 \%$ of total emissions in Hungary, with dynamic growth exceeding $6 \%$ per year. The industry is responsible for 14 million tonnes of $\mathrm{CO}_{2}, 52 \%$ of which comes from passenger cars and $46 \%$ from lorries. The share of rail transport in emissions is less than $1.5 \%$. The percentage of air and waterborne transport is negligible, amounting to $1 \%$ (Fig. 1).

Except for the 2009-2013 period, car emissions are growing at $5-8 \%$ per year, driven primarily by the expansion of the car fleet. The number of cars per 1000 inhabitants in Hungary is relatively low among the EU Member States, only Romania and Latvia have fewer vehicles per capita (Fig. 2). The secondary driving force may be the carbon intensity of cars $\left(\mathrm{CO}_{2}\right.$ emissions per year of use of a car, Fig. 3), in Hungary the carbon intensity of the car fleet is the $7^{\text {th }}$ best in the European Union. This is due to the relatively low mileage of cars in Hungary and the relatively high proportion of "small cars" in the stock.

The $\mathrm{CO}_{2}$ emissions from freight transport are growing at a rate of $6-10 \%$ per annum, well above GDP growth, 


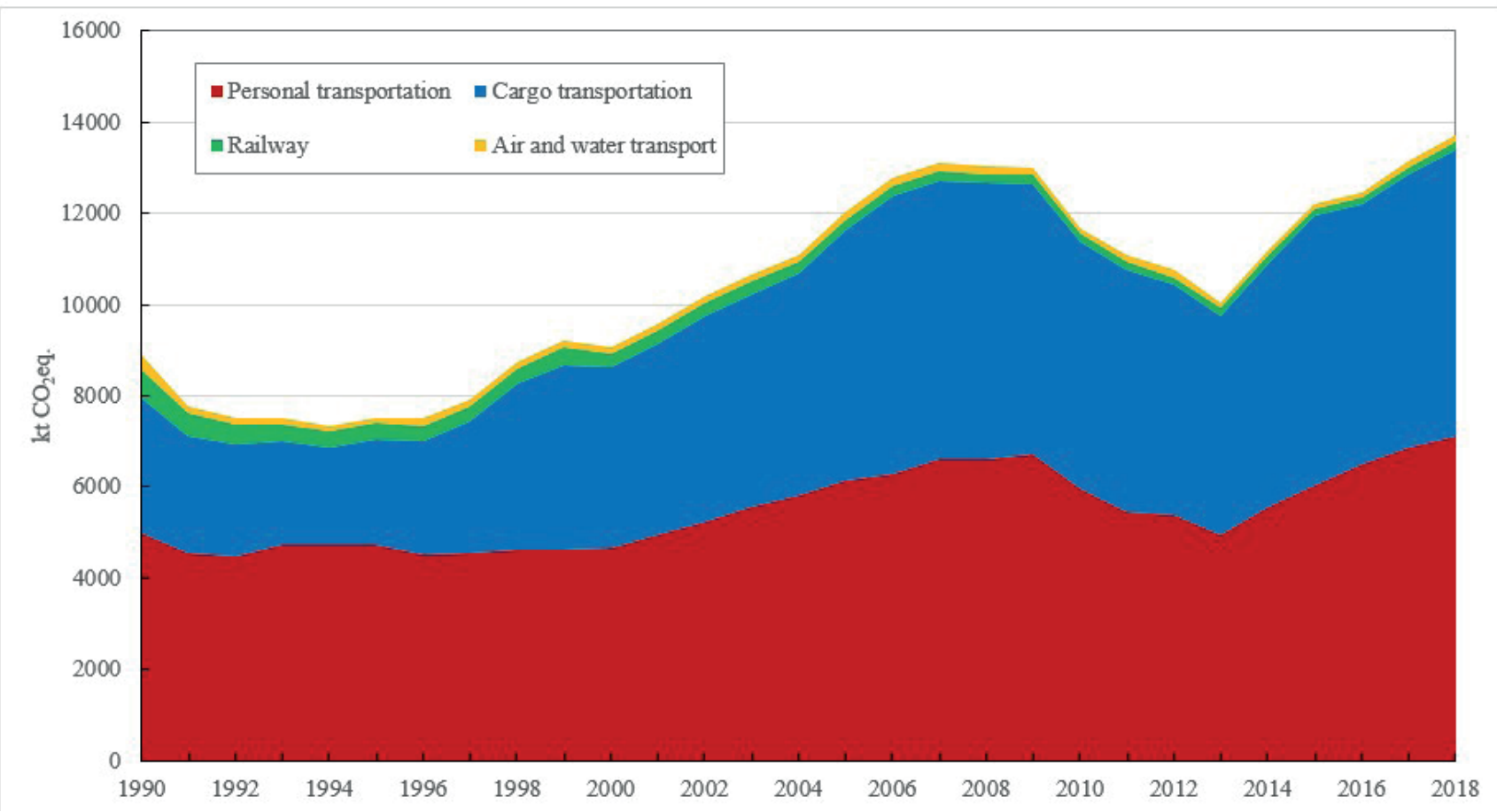

Fig. 1 Changes in carbon dioxide emissions of the Hungarian transport sector (Eurostat, 2020)

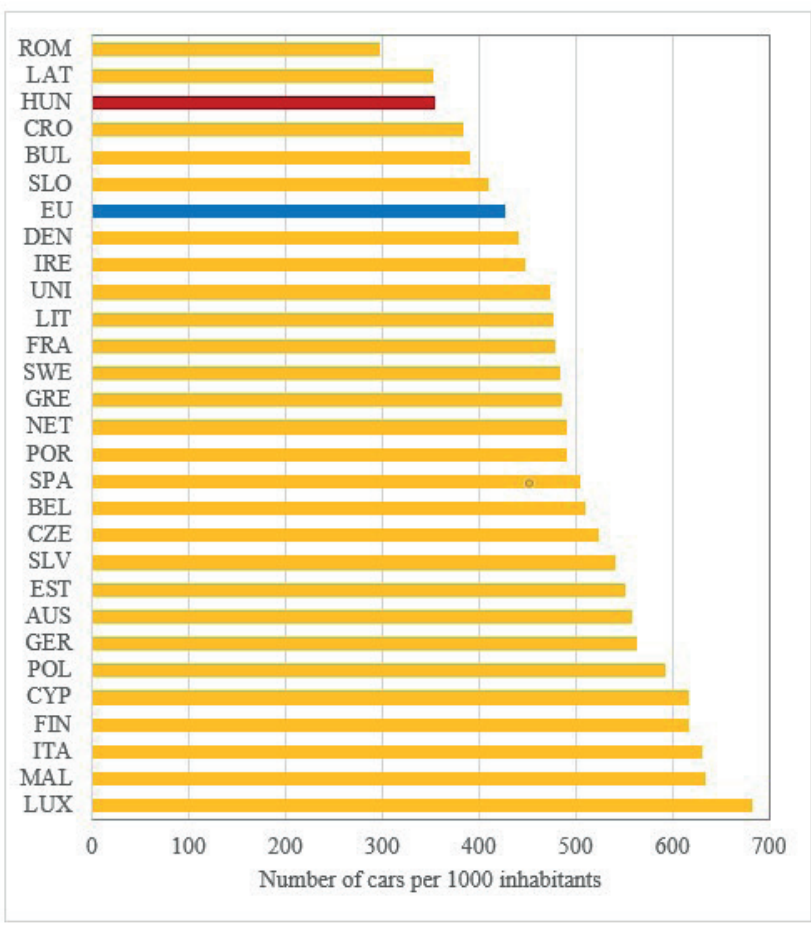

Fig. 2 Number of cars per 1000 inhabitants, 2018 (Eurostat, 2020)

driven mainly by a sharp increase in transportation demand. Looking at the volume of freight transport by mode of transport, it can be seen that in 201840 million tons of goods were transported by road and 10.5 million tons by rail. Considering the decarbonization potential of the main modes of freight transport, we find drastic differences: the transport

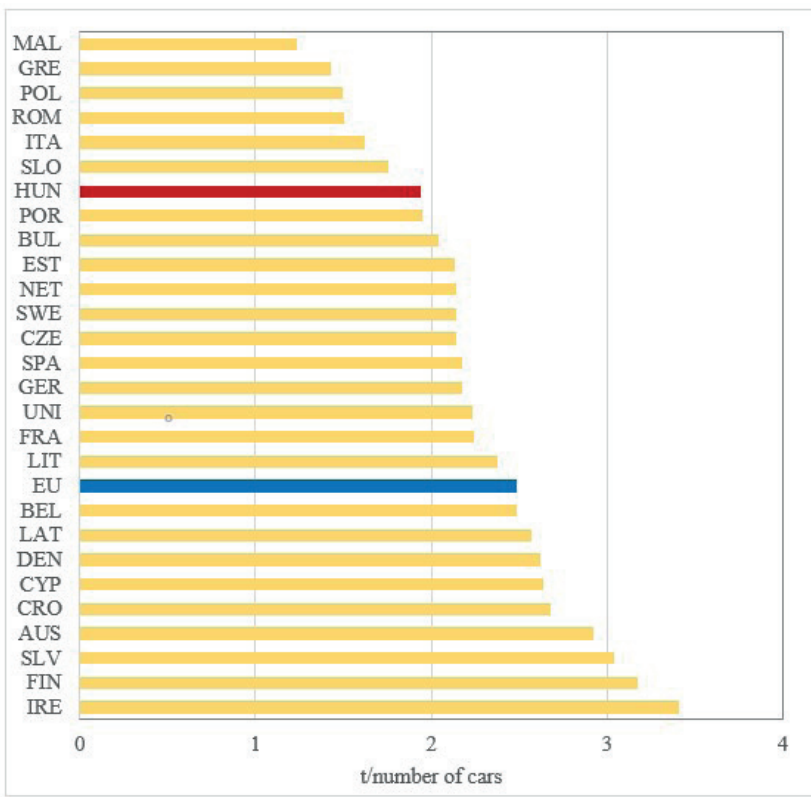

Fig. 3 Carbon intensity, 2018 (Eurostat, 2020)

of 1 million tonnes of goods by road leads to 151 tonnes of $\mathrm{CO}_{2}$. In comparison, the same transport by rail produces only 14.4 tonnes of emissions. Rail transport has an order of magnitude better carbon intensity due to the electrification of the main railway lines and the relatively low fossil content of the Hungarian electricity mix (high import and nuclear ratio). This also means that rail freight transport is the primary driver of decarbonization in freight transport. 


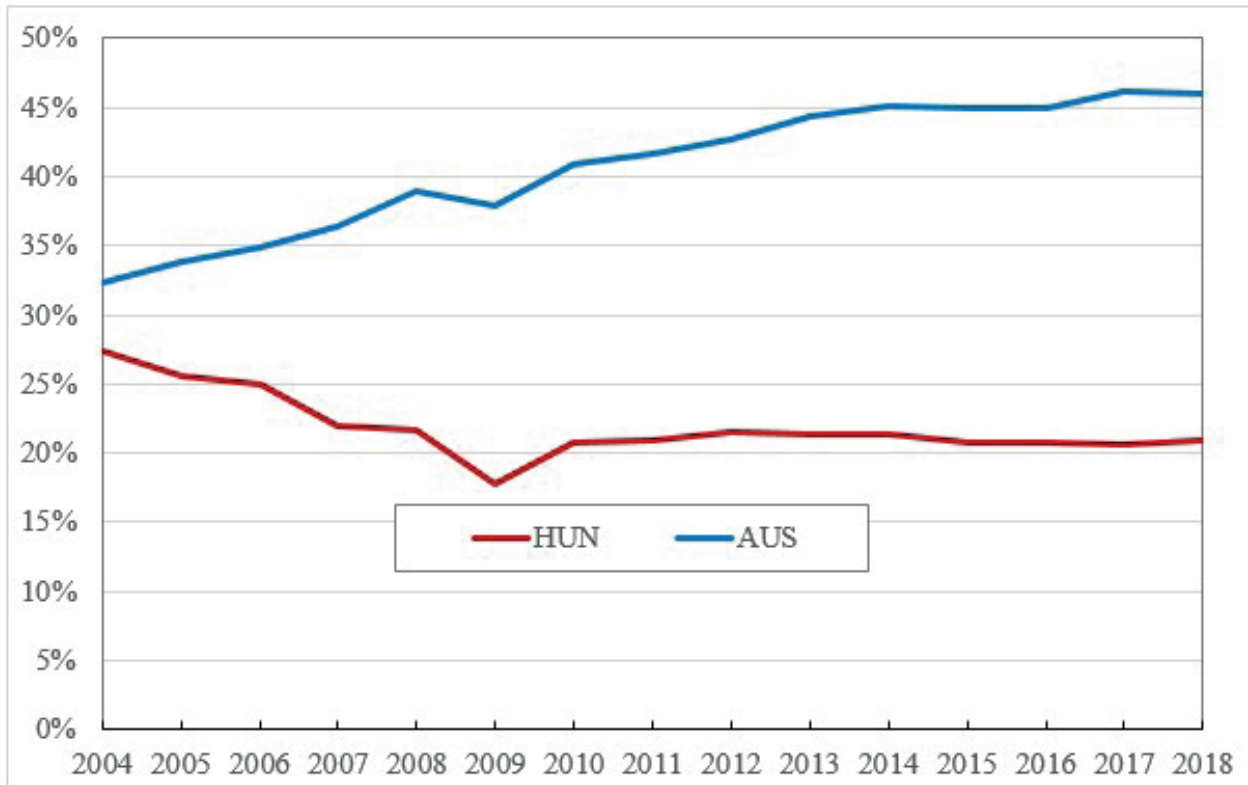

Fig. 4 Ratio of rail freight to total freight in Austria and Hungary (Eurostat, 2020)

Rail freight transport in Hungary has stagnated at around $21 \%$ since the beginning of 2010, while in Austria it has continued to grow at over $45 \%$ (Fig. 4).

\section{Conclusion}

The number of cars per 1000 inhabitants is expected to increase significantly by 2030. Carbon intensity is likely to worsen as the customer's behavior permanently prioritizes larger vehicles. By 2030, there is no realistic potential for decarbonization in the passenger car sector, and even if current trends continue, emissions could increase by an additional 1.5 million tonnes. As shown in the literature, the proliferation of electric cars has a long-term effect. It is not expected to have a significant impact on the $\mathrm{CO}_{2}$ emissions of the whole population by 2030 .

In terms of freight transport, further growth in freight volumes is likely to stop and the resulting $\mathrm{CO}_{2}$ emissions to stabilize at around 6.5 million tonnes. At the

\section{References}

Abrell, J. (2010) "Regulating $\mathrm{CO}_{2}$ emissions of transportation in Europe: A CGE-analysis using market-based instruments", Transportation Research Part D: Transport and Environment, 15(4), pp. 235-239. https://doi.org/10.1016/j.trd.2010.02.002

Andreoni, V., Galmarini, S. (2012) "European $\mathrm{CO}_{2}$ emission trends: A decomposition analysis for water and aviation transport sectors", Energy, 45(1), pp. 595-602.

https://doi.org/10.1016/j.energy.2012.07.039

Buzási, A., Csete, M. (2016) "Modified Scorecard Method for Evaluating Climate Aspects of Urban Transport Systems", Periodica Polytechnica Social and Management Sciences, 24(1), pp. 65-73. https://doi.org/10.3311/PPso.7991 same time, we have significant decarbonization reserves to direct freight to rail: if rail transport rates were to increase from the current $21 \%$ to $35 \%$, this would save 1 million tonnes of $\mathrm{CO}_{2}$.

\section{Acknowledgement}

This work was supported by the Ministry of Human Capacities [Higher Education Excellence Program, Biotechnology research area of the Budapest University of Technology and Economics (BME FIKP-BIO)]. The research reported in this paper and carried out at the Budapest University of Technology and Economics has been supported by the National Research Development and Innovation Fund (TKP2020 Institution Excellence Subprogram, Grant No. BME-IE-BIO) based on the charter of bolster issued by the National Research Development and Innovation Office under the auspices of the Ministry for Innovation and Technology.

Casals, L. C., Martinez-Laserna, E., García, B. A., Nieto, N. (2016) "Sustainability analysis of the electric vehicle use in Europe for $\mathrm{CO}_{2}$ emissions reduction", Journal of Cleaner Production, 127(20), pp. $425-437$.

https://doi.org/10.1016/j.jclepro.2016.03.120

Eurostat (2020) "Air emissions accounts by NACE Rev. 2 activity", [online] Available at: https://appsso.eurostat.ec.europa.eu/nui/show.do?dataset=env_ac_ainah_r2\&lang=en [Accessed: 22 February 2020]

European Commission (2011) "COM/2011/0144 final/EC, White paper, Roadmap to a Single European Transport Area - Towards a competitive and resource efficient transport system", European Commission. 
Hook, W. (1999) "The political economy of post-transition transportation policy in Hungary", Transport Policy, 6(4), pp. 207-224. https://doi.org/10.1016/S0967-070X(99)00022-0

Kim, N. S., Wee, B. V. (2009) "Assessment of $\mathrm{CO}_{2}$ emissions for truckonly and rail-based intermodal freight systems in Europe", Transportation Planning and Technology, 32(4), pp. 313-333. https://doi.org/10.1080/03081060903119584

Koponen, K, Soimakallio, S, Tsupari, E., Thun, R., Antikainen, R. (2013) "GHG emission performance of various liquid transportation biofuels in Finland in accordance with the EU sustainability criteria", Applied Energy, 102, pp. 440-448. https://doi.org/10.1016/j.apenergy.2012.07.023

Kousoulidou, M., Ntziachristos, L, Mellios, G., Samaras, Z. (2008) "Road-transport emission projections to 2020 in European urban environments", Atmospheric Environment, 42(32), pp. 7465-7475. https://doi.org/10.1016/j.atmosenv.2008.06.002

Ministry for Innovation and Technology (2019) "Jedlik Ányos Plan 2.0", Ministry for Innovation and Technology, Budapest, Hungary.

Ministry for Innovation and Technology (2020a) "National Energy Strategy", Ministry for Innovation and Technology, Budapest, Hungary.

Ministry for Innovation and Technology (2020b) "National Energy and Climate Plan", Ministry for Innovation and Technology, Budapest, Hungary.
Pasaoglu, G., Honselaar, M., Thiel, C. (2012) "Potential vehicle fleet $\mathrm{CO}_{2}$ reductions and cost implications for various vehicle technology deployment scenarios in Europe", Energy Policy, 40, pp. 404-421. https://doi.org/10.1016/j.enpol.2011.10.025

Ritchie, H., Roser, M. (2020) " $\mathrm{CO}_{2}$ and Greenhouse Gas Emissions", [online] Available at OurWorldInData.org. Retrieved from: https:// ourworldindata.org/co2-and-other-greenhouse-gas-emissions [Accessed: 22 February 2020]

Tánczos K., Török, Á. (2008) "Impact of transportation on environment", Periodica Polytechnica Transportation Engineering, 36(1-2), pp. $105-110$.

https://doi.org/10.3311/pp.tr.2008-1-2.19

Török, Á. (2014) "Environmental comparism of road and railway transport: A case study in Hungary", International Journal for Traffic and Transport Engineering, 4(2), pp. 210-219. https://doi.org/10.7708/ijtte.2014.4(2).07

United Nations Framework Convention on Climate Change (UNFCCC) (2015) "Report of the Conference of the Parties on its twenty-first session, held in Paris from 30 November to 13 December 2015", United Nations, Paris, France, Rep. FCCC/CP/2015/10.

Vörösmarty, G., Dobos, I. (2019) "Supplier Evaluation with Environmental Aspects and Common DEA Weights", Periodica Polytechnica Social and Management Sciences, 27(1), pp. 17-25. https://doi.org/10.3311/PPso.11814 